Publicación del Seminario "Ángel González Álvarez" de la Fundación Universitaria Española

Número monográfico sobre Mujer y cambio social Año 2021

\title{
Reflexión para una renovación social: Belleza y mujer
}

\section{Reflection for a social renewal: beauty and women}

\author{
FERmina Álvarez Alonso \\ Pontificia Universidad Lateranense \\ Instituto Pastoral Redemptor Hominis \\ Ciudad del Vaticano. Italia) \\ ID ORCID 0000-0001-8479-0940 \\ alvarezalonso@pul.it
}

Recibido: 18-04-2021 | Revisado: 25-05-2021

Aceptado: 27-05-2021 | Publicado: 26/11/2021

DOI: https://doi.org/10.51743/cpe.199

RESUMEN: La presente reflexión propone la Via pulchritudinis como alternativa educativa para la reconstrucción de una sociedad pos-Covid. Desde el significado del concepto de belleza se puede despertar en el ser humano cuanto en él hay de bello, de bueno y de verdadero según la imagen y semejanza de su Creador. La belleza, a la que la mujer es especialmente sensible, en su más alto significado moral, puede ser un medio válido de "humanización" y de transformación social y en este empeño, la mujer puede jugar un papel importante. Sin embargo, para incrementar la influencia y empoderamiento de la mujer, hay que tener presente una concepción antropológica dual que tenga en cuenta, no solamente los elementos comunes al ser humano sino, sobre todo, lo que es específico en ella como "ser femenino". Si el 
grado de belleza de una persona está vinculado a su interioridad, entonces ¿qué características hacen particularmente bella a la mujer? Teniendo como referencia a María, icono de belleza para la mujer y para la Iglesia, se proponen algunos elementos que conforman su belleza: su aspecto profético, su maternidad natural y espiritual y su esponsalidad.

PALABRAS CLAVE: belleza, educadora, esposa, maternidad, mujer.

ABSTRACT: This reflection proposes the Via pulchritudinis as an educational alternative for the reconstruction of a post-Covid society. The concept of "the beautiful" can awaken in the human person the goodness, beauty and truth within them, as made in the image and likeness of the Creator. Women are especially sensitive to beauty and, in its highest moral meaning, beauty can be a valid means of "humanization" and social transformation. Women play an important role in this matter. However, it is necessary to bear in mind the dual anthropological understanding of the feminine that takes into account not only the elements common to the human being but, above all, what is specific in it as "being female". If a person's beauty is linked to their interiority, then what characteristics make a woman particularly beautiful? Taking Mary as a reference and as icon of beauty for women and for the Church, the elements that make up her beauty are her prophetic aspect, her natural and spiritual motherhood, and her nuptiality.

KEYWORDS: Beauty, educator, wife, maternity, women.

\section{INTRODUCCIÓN}

T a crisis provocada por la pandemia del Covid-19 ha marcado profundaLmente la vida del mundo. No sólo ha afectado al modo de relacionarse entre las personas, sino que también ha generado fracturas en la diplomacia entre los Estados, lo cual, deberá ser tenido en cuenta en la futura reconstrucción del tejido social. Será necesario renovarse interiormente, cambiar ciertas costumbres, invertir en confianza hacia los demás y en las relaciones a todos los niveles. El Papa Francisco, en su discurso a la $75^{\text {a }}$ Asamblea General de las Naciones Unidas, propuso la urgencia de la solidaridad global y de un multilateralismo reforzado para afrontar la pandemia del Covid-19 como una única familia humana, con un cuidado particular hacia los más 
vulnerables (Francisco, 2020). Renovó la llamada a servirse de la crisis actual como una oportunidad para promover la paz y la amistad social entre los líderes mundiales, favoreciendo un cambio en las mentes y en los corazones contra la "cultura del descarte", que promueve «una gran falta de respeto por la dignidad humana, una promoción ideológica con visiones reduccionistas de la persona, una negación de la universalidad de sus derechos fundamentales, y un deseo de poder y de control absolutos que domina la sociedad moderna de hoy» (Francisco, 2020).

En este contexto, un signo de nuestros tiempos es la creciente conciencia del papel de la mujer en la sociedad, aunque, paradójicamente, todavía en algunas partes del mundo siga siendo objeto de abusos y discriminaciones. Si la mujer está llamada a tener más espacio y reconocimiento dentro y fuera de la Iglesia ¿qué tipo de protagonismo le corresponde? ¿Cuál sería el adecuado para ella? Todavía resuenan actuales las palabras que los padres conciliares dirigieron a las mujeres al concluirse el Vaticano II: «en este momento en que la humanidad conoce una mutación tan profunda, las mujeres llenas del espíritu del evangelio pueden ayudar mucho a que la humanidad no decaiga» (Pablo VI, 1965). Si la mujer es reconocida como custodia de la humanidad, en la reconstrucción de una sociedad pos-Covid ¿cuáles son los recursos y medios con los que puede contar para ayudar al cambio favorable que el mundo necesita? La historia de la humanidad, maestra de vida, nos ha regalado valiosos ejemplos en sus momentos críticos: ejemplos de mujeres intrépidas, que dieron prueba de coraje y valentía en arrostrar la defensa de situaciones injustas o vulnerables, y gracias a las cuales se suscitó un nuevo viraje en el camino de la sociedad, en la política, en el mundo de las artes, de la religión y de la cultura. Hay muchas fundadoras y santas que, respondiendo a un carisma particular del Espíritu, dedicaron su vida a curar las lacras y carencias sociales de su tiempo. Desgraciadamente, tampoco han faltado ejemplos negativos de mujeres que, movidas por ciertas filosofías o ideologías, han perjudicado y puesto en peligro la dignidad humana. Es el misterio de la libertad humana. Con todo, puede decirse que, en esta pos-modernidad "líquida", sometida a la presión de crisis y de cambios, nos encontramos en un momento favorable para que la mujer pueda dar lo mejor de sí misma y que sea revalorizado lo que en ella es esencial. Para ello, creemos que sea 
necesario, ante todo, conocer las capacidades naturales con las que el Creador la ha dotado, reconocer y salvaguardar aquello que es genuinamente femenino, connatural, que no es algo "impuesto" o accidental construido por una ideología o costumbre social.

Entre otras cualidades, además de la capacidad de generar vida y de donación de sí misma -aspecto en el que supera al ser masculino- una de las notas especiales de la mujer es su sensibilidad por captar el sentido estético de lo bello, que va unido al sentido de lo trascendente y a su intuición espiritual por la cual puede leer más allá de las apariencias, penetrarlas con una mirada amplia y proyectarlas con un significado profético sobre el horizonte. Podemos preguntarnos entonces ¿por qué no utilizar este elemento en la reconstrucción de la resiliencia del tejido social? ¿En qué consiste esta opción por lo bello? ¿De qué medios valerse? ¿Cuál es el aporte que en este sentido puede hacer la mujer a la sociedad? Si con palabras de Dostoievski, «la belleza salvará al mundo», se trata de recuperar la propuesta antropológica que el arte contemporáneo ha perdido. Como ya apuntaba Sedlmayr: «sólo habrá futuro artístico si se logra colocar en ese centro antropológicamente vacío del arte contemporáneo, de nuevo al hombre en toda su plenitud, [...] el hombre-perfecto, el Dios-hombre» (Rouco, 2008, 108). A la luz de Cristo y de su misterio encarnado, resplandece la antropología dual que caracteriza la naturaleza humana y, con ella, las características que connotan la belleza del "ser mujer". Ésta, en nombre de una presunta liberación del dominio del hombre, «no puede tender a apropiarse de las características masculinas y descuidar su propia "originalidad" femenina», pues por este camino no sólo no lograría la ansiada "realización", sino que «podría deformar y perder lo que constituye su riqueza esencial» (Juan Pablo II, 1988, 10).

\section{A PROPÓSITO DEL CONCEPTO DE BELLEZA}

En el corazón de todo hombre y mujer existe un interrogante urgente, latente, siempre presente: ¿qué cosa es la belleza, para conducir «todos los hombres de buena voluntad, en los cuales, de modo invisible actúa la gracia», hacia «el hombre perfecto» que es «imagen del Dios invisible $(\mathrm{Col} 1,15) »$ 
[GS 22]. Sin pretender que sean exhaustivas, a modo de premisa, nos baste recordar algunas notas sobre el significado que el concepto ha recibido a lo largo del tiempo.

La Sagrada Escritura contiene numerosas referencias a la belleza, especialmente en el contexto de la alabanza a Dios en las obras de la creación, en los Salmos y en los libros sapienciales. Se celebra la belleza de la persona (Gen 12,11; 39,6; 1Sam 16,12), del amor humano (Ct 1,14; 4,7; 7,6), la belleza de la Ley y de la casa de Dios, y la belleza de las obras que el hombre, en virtud de su dignidad trascendente, es capaz de realizar. Bondad y belleza convergen de tal manera que los dos términos son intercambiables. Por ejemplo, la cadencia de cada uno de los días que ritman la narración de la creación concluye con la expresión "vio Dios que era cosa buena", pero en el caso de la creación del hombre y de la mujer, el narrador precisa que "era cosa muy buena" y la versión griega de los LXX traduce el calificativo "buena" por kalós, lo cual significaría "y vio que era cosa bella". Así el cielo y la tierra vienen presentados como una "obra de arte" en la que el ser humano resulta ser el ápice de la misma. La belleza-bondad de esta "obra de arte" refleja, por lo tanto, una nota del Creador. A Dios nadie le ha visto jamás -afirma la Escritura- pero, en cambio, se le puede reconocer en sus criaturas: «a partir del movimiento y del devenir, de la contingencia, del orden y de la belleza del mundo se puede conocer a Dios como origen y fin del universo» (Catecismo, 32).

En el ámbito filosófico, el concepto de belleza y de estética como objeto de estudio es relativamente moderno, aunque el sentido innato por la belleza y la estética sea tan antiguo como el hombre. En la Antigüedad clásica la belleza era considerada, en cierto sentido, la expresión visible del bien, como el bien era la condición metafísica de la belleza. La palabra kalón, que nosotros traducimos por "bello", en realidad tenía un significado más amplio respecto al actual: comprendía no sólo lo que resultaba grato al ojo y al oído, sino también la cualidad del carácter y de la mente humana. Los antiguos mantenían separadas la esfera de lo bello y la del arte y conferían a la belleza un fundamento ontológico, para buscar sus manifestaciones en la naturaleza y, en particular, en el cuerpo del hombre, el más noble y alto entre los seres naturales. Precisamente por 
este primado, el hombre era capaz de expresar su belleza, además de en las proporciones de las formas físicas, también en la dignidad de los comportamientos: de aquí derivaba el fuerte vínculo entre bello y bueno, que en la Grecia clásica encontraba su expresión suprema en el ideal formativo de la kalokagathía, la condición propia de quien se puede mostrar, al mismo tiempo, bello y bueno. Bueno, agathós, representaba el aspecto moral, unido a los aspectos social y mundano, que provenía de los orígenes; bello, kalós, se refería a la belleza física, con la inevitable aura erótica y sensual que lo acompañaba (Álvarez Alonso, 2013, 169). Platón escribía a propósito: la potencia del bien se ha refugiado en la naturaleza de lo bello. Ciertamente, es viviendo y trabajando como el hombre establece la propia relación con el ser, con la verdad y con el bien, y por ello, también el artista vive una peculiar relación con la belleza cuando reproduce o crea su obra. Vemos, así, que el concepto de belleza presenta unidas diversas facetas.

San Agustín concebía la belleza espiritual como belleza de la sabiduría, y en su fin último de desear y conocer a Dios, esa era para el hombre una «vía» por la que llegar hasta el Creador. A tal propósito afirmaba: «pregunta a la hermosura de la tierra, pregunta a la hermosura del mar, pregunta a la hermosura del aire dilatado y difuso, pregunta a la hermosura del cielo, pregunta al giro ordenado de los astros [...]. Todos te responderán: «Mira, somos bellos». Su hermosura es su confesión. ¿Quién hizo estas cosas bellas, aunque mudables, sino el inmutablemente bello? [Pulcher]» (Sermones 241, 2).

La teología cristiana, por su parte, ha asumido la estética del mensaje bíblico haciendo converger bondad, verdad y belleza que, junto con la unidad, constituyen los atributos "transcendentales del ser" y que la teología aplica a Dios-creador, causa y plenitud del ser, quien hace partícipes de ellos a sus criaturas según los diversos grados de perfección (Tanzella-Niti y Strumia, 2002, 180). Los tres conceptos están vinculados entre sí. Para santo Tomás, lo bello y el bien son lo mismo porque ambos tienen un único fundamento, la forma, aunque difieren en la razón. El bien va referido al apetito que es como una tendencia a algo que es bueno. Lo bello, por su parte, va referido al entendimiento: se llama bello a lo que agrada a la vista. De ahí que lo bello 
consista en una adecuada proporción, porque el sentido se deleita en las cosas bien proporcionadas como semejantes a sí (Summa, I, q.5). Para el Aquinate, existen tres tipos de belleza: 1) belleza inteligible (vinculada con la verdad y la bondad moral) y en este sentido, la fealdad (que se definirá como privación de belleza) se identifica con el error, la ignorancia, el vicio o el pecado; 2) belleza natural, que procede de la naturaleza de las cosas, reflejos del Creador; por último, 3) belleza artificial, que podemos encontrar en la practicidad de las obras humanas (el arte o las bellas artes, cuyo propósito es la producción de obras bellas y armónicas).

La belleza "natural" que afecta al aspecto antropológico del hombre y de la mujer muestra la verdad, bondad y pureza de Dios, atributos que poseen por haber sido creados "a imagen y semejanza" $(G n 1,26)$, al igual que la belleza de lo creado; la belleza de las artes aplicadas refleja, a su vez, la interioridad del ser humano, cuanto hay en él de verdad y de bien, que logra plasmar y transmitir con su obra. Se podrá afirmar, por lo tanto, que la "belleza" de la obra artística será tal en la medida en que su autor ha logrado reflejar en ella los rasgos de su ser "a imagen y semejanza" de Aquel al que todo está ordenado, como a su fin último, Belleza infinita. En este sentido, la belleza tiene una importancia fundamental para el hombre, pues ennoblece y eleva su espíritu. Las cosas bellas, en efecto, poseen un bien objetivo para la existencia del hombre. Para la ecología del espíritu, es urgente comprender cuán terrible empobrecimiento, deterioro y perjuicio para la existencia humana se anida en la "des-poetización" de la vida, en la destrucción de la belleza de la naturaleza y, sobre todo, de la belleza del arte (Hildebrand, $2006,9)$. No hay conflicto entre verdad y belleza, porque lo bello se convierte en vía para alcanzar lo verdadero, y el conocimiento de la verdad conduce a la experiencia de la alegría y de la belleza. Por ello, ésta es también una de las grandes fuentes de felicidad para la vida humana, que tiene variedad de gradaciones según la sensibilidad del individuo (Hildebrand, 2006, 10). Con Pablo VI podemos afirmar que «el mundo en que vivimos tiene necesidad de belleza para no caer en la desesperación. La belleza, como la verdad, trae el gozo al corazón de los hombres y es un fruto precioso que resiste el paso del tiempo, que une a las generaciones y las hace comulgar con la admiración» (Pablo VI, 1965). En este sentido, Hans Urs Von Balthasar relaciona la be- 
lleza con la Gloria de la que lo creado es una manifestación, «es la aureola de resplandor imborrable que rodea a la estrella de la verdad y el bien y su indisociable unión» (Balthasar, 1985).

El Papa Francisco, comentando la obra de Dante con ocasión del séptimo centenario de su muerte, reconoce que la teología y la filosofía tienen una especial relación con la belleza artística, pues ésta dota «a la doctrina de su apariencia y ornamento, con la dulzura del canto y la visibilidad del arte figurativo y plástico, abre el camino para que sus preciosas enseñanzas se comuniquen a muchos.[...] el señor del altísimo canto [Dante] convirtió la belleza en sierva de la bondad y la verdad, y la bondad materia de belleza» (Francisco, 2021). Vemos, pues, que la promoción de aquellas artes figurativas que contienen de algún modo los atributos divinos de verdad, bondad y armonía, son un medio que ennoblece y eleva al ser humano en su proceso de desarrollo hasta completar su ser "imagen y semejanza" del Creador, lo cual no es otra cosa sino el testimonio de una santidad de vida inspirada por el Espíritu.

\section{EDUCAR EN LA BELLEZA COMO PROYECTO DE HUMANIZACIÓN}

Educar la sensibilidad por la belleza a través del arte del símbolo, promoviendo a su vez el desarrollo de la racionalidad por la verdad, podría abrir una puerta hacia una más alta moralidad, y sería una respuesta constructiva al relativismo que nos invade, a la crisis antropológica que sufrimos y a la pobreza cultural que de ella se deriva. La belleza espiritualiza. Si toda la practicidad de la vida viene impregnada de belleza, se crea entonces un gran valor que viene a nutrir constantemente nuestro espíritu mediante el contacto con un mundo superior -con la cultura en el sentido especifico, a diferencia de la mera civilización-. En cambio, el predominio del punto de mira práctico, provoca una "des-poetización" de la vida que para la felicidad y salud humanas tiene consecuencias más graves de lo que pudiera creerse (Hildebrand, 2006). Y es que la conformidad de la mente y del corazón a Dios motiva y eleva el ingenio (Hildebrand, 2006). En su Carta a los artistas, Juan Pablo II desarrolla el paralelo entre bondad y belleza, entre experiencia estética y experiencia religiosa. Los "momentos de gracia" o de inspiración se producen cuando el espíritu 
creador que une en sí lo bueno y lo bello, despierta en el hombre las energías de la mente y del corazón haciéndolo capaz de concebir la idea y de plasmarla en la obra de arte. Se trata de una experiencia de aquel Absoluto que trasciende al hombre sin anularlo (Juan Pablo II, 1999). En este sentido, la obra dantesca de La Divina comedia define el término "transhumanizar", como el esfuerzo por «conseguir que el peso de lo humano no destruya lo divino que hay en nosotros, ni tampoco que la grandeza de lo divino anule el valor de lo humano» (Francisco, 2021, 1). Tenemos ejemplos en la pluma de mujeres como Teresa de Jesús, Catalina de Siena o Hildegarda de Bingen, grandes místicas, y a la vez, mujeres implicadas socialmente en la reforma de su tiempo, declaradas Doctoras de la Iglesia por la elevada intuición de sus doctrinas y su conocimiento y enseñanza de las cosas divinas. En ellas la compatibilidad de la experiencia religiosa y la inspiración han tomado cuerpo en un peculiar estilo literario y artístico.

La sensibilidad por la belleza duerme escondida en ese rincón del corazón humano que guarda sus capacidades y aptitudes. Despertar el sentido de lo estético, el gusto por la armonía, y la disposición de la voluntad para dejarse capturar interiormente en la contemplación de la certera claridad para adherirse a ella, bien podría ser tarea de una educación que busque el desarrollo integral y armónico de la persona. "La naturaleza esculpe un hombre nuevo», afirmaba un gran educador contemporáneo (Morales, 2011). Por ello, incorporemos en la educación iniciativas tendentes a suscitar el asombro ante lo bello, el sentido de lo trascendente, el gusto por todo aquello que es "epifanía", "habla" de Dios, para generar en torno un benéfico influjo de los atributos contenidos de belleza, de bien y de verdad. Estos están de tal modo interconectados entre sí que el crecimiento de uno lleva al aumento de los otros, como en el sistema de vasos comunicantes, procediendo hacia la nobleza y humanización del hombre. En una sociedad posmoderna, sin fines ni medios educativos, es difícil educar a los jóvenes en el bien, y a este propósito, el Papa Francisco ha trazado lo que se podría llamar una "pedagogía de la belleza". Es preciso comprometerse con la Via pulchritudinis para

\footnotetext{
${ }^{1}$ Se trata del opúsculo inédito publicado en italiano: J. M. Bergoglio, La bellezza educherà il mondo, Emi, 2014.
} 
ayudar a los jóvenes a desarrollar «un espíritu crítico frente a lo que ofrece la cultura mediática y a plasmar su sensibilidad y su carácter para elevarlos y conducirlos a una auténtica madurez» (Pontificio Consejo de la Cultura, 2008, 45). En esta tarea educativa en beneficio del mundo, la mujer resulta ser especialmente idónea gracias a las características con que ha sido dotada y su aptitud para proteger y hacer desarrollar la vida del hombre con sus dones individuales. Además, la mujer posee la armonía como especial característica de su feminidad. «La unidad, la delimitación y el desarrollo armónico están destinados a indicar la capacidad de acogida de las mujeres, las cuales tienen una estructura unitaria, cuyas partes están armoniosamente conectadas» (Ales, 2021, 135). La tarea de guiar a la madurez las posibilidades específicas del hombre y del niño, lo más genuina y plenamente posible, presupone en la mujer una profunda disposición al servicio y a la dedicación de sí misma (Stein, 2021) que la hacen apta para cuidar de lo frágil y vulnerable, por su amor por lo concreto y su talante para ser "compañera" de vida del ser humano.

Uno de los autores del idealismo estético alemán, Friedrich Schiller, en su obra Cartas sobre la educación estética del hombre (Über die ästhetische Erziehung des Menschen,1795), escrita en el contexto marcado por las ideas laicistas de la Revolución francesa, señalaba la importancia de este tipo de educación como medio de transformación social. Podrán cambiar las circunstancias, las formas, pero como la naturaleza humana será siempre la misma, encontramos actuales algunos de los principios invocados al servicio de una educación estética.

\subsection{Armonizar impulsos y afectos según la razón}

En la séptima carta de su obra, Schiller sienta las bases para desarrollar su proyecto educativo. Reconoce que debe haber una «forma de humanidad» en la base si se desea obtener una mejora moral del Estado. Ello no será posible hasta que no haya sido "superada la división en el interior del hombre y su naturaleza esté lo suficientemente desarrollada como para ser ella la artista y garantizar su realidad a la creación política concebida por la razón» (Schiller, 2019). El modo de hacerlo es sometiendo y ordenando los impulsos y 
afectos primarios a la razón antes de favorecer la multiplicidad, para promover después, una conveniente libertad. Aconseja asumir la propia sensibilidad natural y no prescindir de los sentimientos, sino más bien educarlos y orientarlos para que puedan incidir positivamente en la razón: es el corazón quien debe abrir el camino que lleva al intelecto. La educación del sentimiento es pues la necesidad más apremiante de nuestro tiempo, no sólo porque se vuelve un medio para que sea efectiva en la vida una comprensión mejor de la verdad, sino también porque promueve la mejora de la inteligencia misma (Schiller, 2019, 82).

Y a propósito de la moderación que debe regir los impulsos en la persona, el filósofo alemán se expresa a favor de la complementariedad y la armonía: «la personalidad debe mantener el impulso material dentro de los límites debidos, así como la receptividad o la naturaleza el impulso formal dentro de los suyos» (Schiller, 2019, 102).

\subsection{La belleza como medio de ennoblecer el carácter}

En la ascesis y orden de los sentimientos según la razón, Schiller otorga a la belleza un papel decisivo para ennoblecer el carácter. Toda mejora en la esfera del político proviene de ella. Y se pregunta: ¿cómo se puede ennoblecer el carácter bajo las influencias de una bárbara constitución política? Es preciso buscar un instrumento no proporcionado por el Estado, fuera de su influencia, para descubrir fuentes limpias a pesar de la corrupción política. Este instrumento es el arte bello:

El arte, como la ciencia, gozan de una inmunidad absoluta ante la arbitrariedad humana. [...] Encamina el mundo donde actúas en dirección al bien, que el silencioso ritmo del tiempo traerá el desenvolvimiento. [...] En el silencio pudoroso de tu espíritu cría la verdad triunfante, ponla fuera de ti en la belleza, para que no sólo el pensamiento se le rinda, sino que también los sentidos acojan amorosamente su manifestación (Schiller, 2019, 83).

Contemplada con ánimo puro, «la belleza habla directamente al corazón, eleva interiormente desde el asombro a la maravilla, de la felicidad a la contemplación. Por ello, crea un terreno fértil para la escucha y el diálogo con el hombre y para llegar a él en su integridad, mente y corazón, inteligencia y razón, 
capacidad creativa e imaginación» (Pontificio Consejo de la Cultura, 2008, 49). Esa contemplación ayuda al hombre a volver en sí, a no dejarse atrapar por la practicidad de la vida diaria, llena de exigencias profesionales o de lucha por la supervivencia, en que la jornada se reduce a una sucesión práctica de asuntos que resolver. En este caso, la contemplación de algo bello puede ayudar a espiritualizar al hombre y a liberarlo del pragmatismo (Hildebrand, 2006), pues la belleza tiene un poder transformante. Al expresar todo cuanto hay de bueno y de veraz en el interior del hombre, la manifestación de su apariencia no deja indiferente, ejerce un positivo influjo en los sentidos, despierta la atracción y el deseo por el bien, «pone en movimiento un dinamismo de profunda transformación interior que genera gozo, sentimiento de plenitud, deseo de participación gratuita en la misma belleza, de apropiársela interiorizándola e insertándola en la propia existencia concreta» (Pontificio Consejo de la Cultura, 2008, 49). Todo lo que hacemos y cómo lo hacemos debería ser bello. Dante, «profeta de esperanza y testigo de la sed de infinito ínsita en el corazón del hombre» (Pontificio Consejo de la Cultura, 2008, 120), persigue un objetivo transformante con su obra $L a$ Divina comedia, pues ésta «no sólo se propone ser poéticamente bella y moralmente buena, sino capaz de cambiar radicalmente al hombre y llevarlo del desorden a la sabiduría, del pecado a la santidad, de la miseria a la felicidad, de la contemplación aterradora del infierno a la contemplación beatífica del paraíso» (Francisco, 2021).

\subsection{Educar en la belleza es educar en la libertad}

Como existe una educación en la salud, una educación de la inteligencia, una educación en la moralidad, la educación por el gusto y por la belleza tiene como objetivo desarrollar el conjunto de nuestras capacidades sensibles y espirituales con la máxima armonía posible. Un fruto de la educación que haya logrado armonizar los impulsos interiores del hombre es la libertad que, según Schiller, es un efecto de la naturaleza, y ella «principia sólo cuando el hombre está completo y cuando sus dos impulsos fundamentales se han desarrollado» (Schiller, 2019). El paso del estado pasivo del sentir al activo del pensar y del querer sucede a través de un estado intermedio de libertad estética, como condición necesaria para llegar a una verdad o a una disposición 
moral. «Para hacer del hombre sensible un hombre racional, no hay otro camino que volverlo, primero, un hombre estético» (Schiller, 2019, 136). Una de las incumbencias más señaladas de la cultura consiste pues en volver al hombre estético, «porque sólo a partir del estado estético, y no del físico, puede desarrollarse el estado moral» (Schiller, 2019, 136). Con todo, existe el peligro de quedarse en el fenómeno de la experiencia. «El hombre corre el riesgo de dejarse atrapar por una belleza tomada por sí misma, icono convertido en ídolo, medio que acaba devorando el fin, verdad que aprisiona, trampa en la que acaban cayendo muchos por falta de una adecuada formación de la sensibilidad y de una correcta educación a la belleza» (Pontificio Consejo de la Cultura, 2008, 45).

Para pasar del estado estético al estado moral, bastan pocas ocasiones importantes, momentos significativos o sublimes en los que, inducidos por las mismas cosas, según la propia disposición natural de los sentidos, se ha tenido una experiencia de lo bello que ha transformado interiormente al hombre en una experiencia estética. La transformación producida por esta experiencia ha sido causada por la verdad y el bien que contienen lo bello. Cada día en el mundo renace la belleza — del bien y de la verdad - que resucita transformada a través de las tormentas de la historia (Francisco, 2013). En palabras de Soloviev, la belleza no es sino la «encarnación, en formas sensibles, del mismo contenido ideal que antes de encarnarse se llamaba bien y verdad» (Soloviev, 1983); éstas, «para realizarse verdaderamente en el sujeto, tienen que convertirse en una fuerza creativa capaz de transfigurar la realidad y no sólo de reflejarla» (Pontificio Consejo de la Cultura, 2008). La belleza, por lo tanto, hace al hombre y a la mujer más "humanos", más verdaderos, y más buenos; todo ello, según la capacidad comunicada a cada uno en el momento de la Creación, y en la medida en que ha correspondido libremente a las inspiraciones del Espíritu.

\section{LA ESPECÍFICA BELLEZA DE LA MUJER}

En un mundo que corre el riesgo de caer en un inquietante embrutecimiento, la vía pulchritudinis se presenta como una válida alternativa de transforma- 
ción del ser humano y una opción para llegar a la verdad o, al menos, para hacerla creíble y atrayente. En este proceso, puesto que se implica la interioridad de la persona, el valor del testimonio juega un papel primordial. Todo cristiano está llamado a ser testigo de la Belleza. Bello, entonces, no sólo valiente y veraz, debe ser el testimonio y la palabra ofrecida, porque bello es el rostro que se anuncia, el de Cristo, que es representación perfecta de la gloria del Padre y que comunica al hombre la plenitud de su gracia, haciéndole grato y agradable a los ojos de Dios.

A este propósito, un primer paso será despertar en sí mismos, pero sobre todo en los hombres y mujeres de nuestro tiempo, la atracción por lo que es bello, verdadero y bueno en su apariencia y, sobre todo, en su significado moral. La falta de verdad y de bien en una sociedad acaban por anular la belleza y es demostración de la «impotencia de la idea» (Soloviev, 1983). Toda ideología carece de un fundamento de principios antropológicos, de aquí su futilidad; la antropología, por el contrario, tiene cuenta de lo concreto, de lo real del hombre, sienta las bases para su consolidación. Por lo tanto, si se quiere incrementar la influencia y el empoderamiento de la mujer es preciso aceptar una concepción antropológica que tenga en cuenta no solamente los elementos del ser humano, sino, además, lo que le es específico como "ser femenino". Si el grado de belleza de una persona está vinculado a su interioridad, cabe preguntarse ¿qué características hacen particularmente bella a la mujer? Volviendo al texto bíblico del Génesis, la "bondad" que se expresa en el momento de la creación del varón y de la mujer es una prueba del reconocimiento del carácter personal del ser humano, creado para la relación recíproca como "unidad de los dos" en su común humanidad y en una comunión de amor (Juan Pablo II, 1988, 7) — de aquí la necesidad de integrar "lo masculino" y "lo femenino"-, que tanto le asemeja a la relación interpersonal en el seno de la Trinidad. El uso de estos adjetivos masculino y femenino - define una característica de la esencia humana, que no es producto de un consenso social. Esta vocación de ser personal, que lo distingue del resto de lo creado, le hace tender a su realización, a «encontrar su propia plenitud en la entrega sincera de sí mismo a los demás» (GS 24). De aquí, que una nota predominante del ser humano sea su capacidad y libertad para el don, para darse en el amor, y para recibir el don del amor. El 
texto bíblico designa a la mujer como "ayuda" del varón. En el Antiguo Testamento el término está asociado con Dios mismo y adquiere el significado de su representante en forma humana.

En la mujer, la capacidad de donación que la asemeja al varón se expresa con características genuinas y originales. Su belleza — «su levedad (vs la gravedad del varón) - , que no es exclusivamente física, es la belleza de la gracia, o sea, de lo gratuito, de su capacidad de entrega. La belleza moral de la mujer, su fuerza espiritual, se une a la conciencia de que «Dios le confía de un modo especial el hombre, es decir, el ser humano» (Juan Pablo II, 1988, 30). A ella corresponde la fuerza de permanencia, la paciencia que necesita el desarrollo humano, la temperancia (la mujer salva al varón de perderse entre el intelecto y la pasión» (Redondo y Gallardo, 2021, 71). A ella ha sido encomendada la tarea de generar y de vigilar sobre la humanidad. Por poner un ejemplo, la reciente experiencia del Covid-19 ha puesto de manifiesto la entrega heroica de tantas mujeres que han luchado contra el virus cuidando a miles de personas en la asistencia social y caritativa de tantos necesitados como ha provocado la pandemia. La mujer está habilitada para generar espacios de vida. Su atención por lo concreto, por la vulnerabilidad del ser humano, por su debilidad y sus necesidades, hacen que el don de sí sea para ella un elemento fundante de su belleza, la belleza de la gratuidad.

Volviendo a Dante Alighieri, vemos que un aspecto de la numerosa presencia femenina que muestra en La Divina comedia es el sentido, en algunas de sus protagonistas, de protección y sostén para con los extraviados y decaídos. Así, Beatriz, personaje que representa la esperanza, durante el viaje al infierno y al purgatorio, anima al poeta en sus momentos difíciles y le da una nueva energía para continuar el camino. A lo largo de su obra, la relación entre los dos es siempre dramática y Dante siempre cede a la mujer que, unas veces se presenta como la guía del poeta, y otras como la madre que reclama al hijo sus deberes.

¿En qué medida — se preguntaba von Hildebrand - podemos designar nuestros actos como portadores de la belleza de nuestra vida vivida? Para el cristiano, mostrar la belleza de una vida transformada por la gracia, es la vía fundamental que lleva a descubrir la belleza del icono de la santidad con la que el Espíritu Santo plasma a su Iglesia. El propio amor tiene relación con 
el tener "conciencia de" la belleza, en cuanto que el amor nos mantiene despiertos hacia todo aquello que contiene belleza, sobre todo, la belleza de la vida, de la naturaleza y del "mundo bello" que nos rodea. De aquí, que la vivencia de nuestra vida se pueda embellecer gracias al ejercicio del amor que, bajo la moción del Espíritu Santo, produzca en nosotros un ex-tasis, un "salir fuera de sí". En este sentido, los frutos espirituales de «amor, alegría, paz, paciencia, afabilidad, bondad, lealtad, modestia, dominio de sí» (Gal 5,22-23) de que habla el apóstol, vividos en el corazón de una mujer, serán otras tantas manifestaciones de esa belleza cristiana que el mundo está reclamando.

Si la belleza del ser humano se realiza en el don de sí, la mujer tiene una mayor predisposición para ello, y lo manifiesta con su sentido profético, maternal y esponsal. El don de profecía, bajo la moción del Espíritu, es esa capacidad para descubrir el sentido y fin de las cosas y acontecimientos según el proyecto de Dios. Este don se encuentra presente entre los carismas que enriquecen y edifican la Iglesia primitiva. Si bien puede ser dado a todos, ha caracterizado de modo peculiar a la mujer, favorecido por su intuición natural y por su especial sensibilidad por las cosas espirituales, y relacionado con su espíritu de observación y de escucha, con un corazón capaz de olvidarse de sí y de amar ordenadamente la realidad concreta. La espiritualidad femenina tiene una particular manifestación en ayudar a los hombres a caminar hacia Dios. La oración de súplica y de acción de gracias que vemos en algunas mujeres del Nuevo Testamento denotan su posición al lado de los débiles, dando voz a los humildes. La mujer tiene una sensibilidad especial que le permite penetrar el sentido de lo real, alcanzar a ver detalles de los avatares y de las cosas - existencialmente importantes - que a los ojos de un interlocutor masculino podrían quizá pasar inadvertidas. El alma de la mujer siente un fuerte deseo natural por los valores que nutren el espíritu. Es receptiva para todo lo bello y se entusiasma fácilmente por aquello que es realmente noble y, sobre todo, está abierta a los valores terrenos más elevados e inefables (Stein, 2012, 141). Saber apreciar y valorar esta capacidad innata en la mujer ayuda a entender la realidad con una visión comprensiva. La mujer observa e interpela su experiencia desde un corazón capaz de amar y de acoger amor (Álvarez Alonso, 2021, 212). 
Por lo que respecta a la maternidad, entendida en su significado más amplio, esa «está unida a la estructura personal del ser mujer y a la dimensión personal del don» (Juan Pablo II, 1988, 18) porque supone la previa disponibilidad para el "don sincero de sí" y la aceptación de una nueva vida. Aquí radica la belleza del ser madre, en esa apertura interior de la mujer para la generación, que dilata su persona, porque en ella se refleja «el eterno misterio del engendrar que existe en Dios mismo, uno y trino (cf. Ef 3,14-15)» (Juan Pablo II, 1988, 18). La mujer es casi la protección y casi la morada de otras almas que en ella se pueden desarrollar. Esta doble función de compañera y de madre no se limita a los estrechos confines de las relaciones matrimoniales y maternas, sino que se extiende a todos los seres humanos que aparecen en su horizonte (Stein, 2012, 137).

Junto con la maternidad, otra característica peculiar que embellece a la mujer es el don esponsal. Esponsalidad, entendida como natural disposición de la persona femenina, llamada a ser amada y a darse en el amor al varón de modo exclusivo en el contexto del matrimonio, con toda su persona, y que se traduce en la solicitud por todos aquellos que tiene a su alrededor, ya sean los miembros de su familia natural -esposo e hijos- ya sean otras personas fuera del entorno familiar. En el caso de las vírgenes consagradas el don esponsal se realiza también dentro de una familia espiritual, dedicadas a atender a cuantos están a su alcance, especialmente los más necesitados, en los que ven reflejado al Esposo virginal por el que han consagrado su vida.

Una obra-modelo del Artista divino en la que toda mujer puede inspirarse es María, icono de belleza, genuino prototipo de feminidad (Stein, 2012, 219). Ella es «el "nuevo principio" de la dignidad y vocación de la mujer, y de todas y cada una de las mujeres» (Juan Pablo II, 1988, 11), en ella se vuelve a aquel "principio" donde se encuentra la mujer como fue requerida en el momento de la creación, según el designio de Dios. La referencia de Dante a María es constante en toda la Divina comedia. En el camino del Purgatorio, es el modelo de las virtudes que se contraponen a los vicios; es la estrella de la mañana que ayuda a salir de la selva oscura para encaminarse hacia el monte de Dios; es la presencia constante, por medio de su invocación - «el nombre de la bella flor que siempre invoco, / mañana y noche» (Par. XXIII, 88-89)-, que prepara al encuentro con Cristo y con el 
misterio de Dios. También hoy el poeta italiano quiere mostrarnos cuál es el itinerario hacia la felicidad, el camino recto para vivir plenamente nuestra humanidad, dejando atrás las selvas oscuras donde podemos perder la orientación y la dignidad (Francisco, 2021).

\section{A MODO DE CONCLUSIÓN}

Teniendo en cuenta el significado que contiene el concepto de belleza y el poder transformante que encierra, utilizado como un fin en la educación, en este breve recorrido hemos querido presentar aquello que, al ser peculiar y genuino en el ser femenino, connota su belleza. Como hemos visto, la Vía pulchritudinis comporta no sólo el aspecto estético-artístico de la apariencia externa de una obra, sino también la carga moral de virtudes y de vivencias que, en cierto modo, reflejan el "ser bueno, bello y verdadero" del DiosCreador. En este sentido, las características y dones con que ha sido configurado el "ser mujer", como son su sensibilidad por lo espiritual y su capacidad de donación, explicitada en una maternidad natural o espiritual y en un amor esponsal, hacen particularmente bella a la mujer. Una belleza que no es sólo física, sino que refleja un vigor interior capaz de sembrar armonía a su alrededor, de sanar y vivificar los corazones de los hombres, como el Espíritu Santo consolador hace con su Iglesia. La mujer prolonga, así, la maternidad y esponsalidad de la Virgo-Mater, y María, a su vez, como hace con toda la actividad de la Iglesia, coopera de modo singular con toda mujer que cumpla su misión femenina y se abandone libremente a ella respondiendo interiormente a la gracia del Espíritu. Ella puede formar su propia imagen en aquellos que le pertenecen (Stein, 2012, 265).

Antes de concluir, me sea permitida todavía una última precisión. No es posible entender de manera aislada, separada del hombre, el rol y la función que la mujer desempeña en la Iglesia y en el mundo, como pretenden las ideologías que fomentan una fragmentación antropológica y social. La mujer ha sido creada para el hombre, porque éste necesita de ella para poder explicar adecuadamente el sentido de su propio ser (Stein, 2012, 214), y viceversa. Sólo desde la perspectiva de la complementariedad, de su relación con el 
"otro-ser masculino", de su rol de "ayuda", de "compañera" del hombre, resplandecen con mayor claridad y verdad esas características genuinas que la hacen particularmente bella a los ojos de Dios y de los hombres. Sólo así la mujer puede llegar a ser ella misma, a completarse y a realizar plenamente su feminidad.

\section{REFERENCIAS BIBLIOGRÁFICAS}

Ales Bello, A. (2021). Maternidad y paternidad desde la perspectiva de la antropología dual de Edith Stein. En L. Redondo Redondo (Coord.) y Gallardo S. (Ed.). Mujer y mujeres. Su esencia y su existencia en la historia. vol. 1: La mujer. Ser y tarea (pp. 129-146). Universidad Católica de Ávila.

Álvarez Alonso, F. (2013). Alla verità per la via della bellezza. En Cuadernos de Pensamiento, 26, 167-199.

Álvarez Alonso, F. (2021). La Iglesia es mujer. En L. Redondo Redondo (Coord.) y S. Gallardo (Ed.). Mujer y mujeres. Su esencia y su existencia en la historia. vol. 1: La mujer. Ser y tarea (pp. 199-230). Universidad Católica de Ávila.

Balthasar, H.U. von (1985). Gloria. La percepción de la forma. Encuentro.

Bergoglio, J. M. (2014). La bellezza educherà il mondo. Emi.

Catecismo de la Iglesia Católica (Cathechismus Catholicae Ecclessiae, 15-VIII1997).

Francisco (25 de marzo de 2021). Carta Apostólica 'Candor Lucis Aeternae' en el VII centenario de la muerte de Dante Alighieri.

https://press.vatican.va/content/salastampa/it/bollettino/pubblico/2021/03/25/0 181/00393.htmlHspa

Francisco (25 de septiembre de 2020). Video-mensaje con motivo del 75 periodo de sesiones de la Asamblea General de las Naciones Unidas.

http://www.vatican.va/content/francesco/es/messages/pont-

messages/2020/documents/papa-francesco_20200925 videomessaggioonu.html

Francisco (24 de noviembre de 2013). Exhortación Apostólica Evangelii gaudium. http://www.vatican.va/content/francesco/es/apost_exhortations/documents/papafrancesco esortazione-ap 20131124 evangelii-gaudium.html

Hildebrand, D. von (2006). Estetica, Bompiani. Juan Pablo II (4 de abril de 1999). Carta a los artistas. http://www.vatican.va/content/john-paul-ii/es/letters/1999/documents/hf_jpii let_23041999_artists.html 
Juan Pablo II (15 de agosto de 1988). Mulieris dignitatem.

http://www.vatican.va/content/john-paul-ii/it/apost letters/1988/documents/hf jpii_apl 19880815 mulieris-dignitatem.html

Morales, T. (2011). Forja de hombres. Biblioteca de Autores Cristianos

Pablo VI (8 de diciembre de 1965). Mensaje del Concilio a las mujeres.

http://www.vatican.va/content/paul-vi/es/speeches/1965/documents/hf_p-

vi_spe 19651208 epilogo-concilio-donne.html

Pablo VI (8 de diciembre de 1965). Mensaje a los artistas.

http://www.vatican.va/content/paul-vi/es/speeches/1965/documents/hf_pvi spe 19651208 epilogo-concilio-artisti.html

Pontificio Consejo de la Cultura (2008). 'Via Pulchritudinis'. Camino de evangelización y de diálogo. BAC Documentos.

Prats Mora, J.I. y Prats Arolas, G. (2021). La mujer como don. En L. Redondo Redondo (Coord.) y Gallardo S. (Ed.). Mujer y mujeres. Su esencia y su existencia en la historia. vol. 1: La mujer. Ser y tarea (pp. 57-78). Universidad Católica de Ávila.

Redondo Redondo, L. (Coord.) y Gallardo S. (Ed.) (2021). Mujer y mujeres. Su esencia y su existencia en la historia. vol. 1: La mujer. Ser y tarea. Universidad Católica de Ávila.

Rouco Varela, A.M. (2008). La belleza frente a la ideología laicista. En Pontificio Consejo de la Cultura. 'Via Pulchritudinis'. Camino de evangelización y de diálogo (pp. 103-111). BAC Documentos.

San Agustín (s.f.). Sermones. 241, 2.

https://www.augustinus.it/spagnolo/discorsi/discorso 337 testo.htm

Schiller, F. (2019). Cartas sobre la educación estética del hombre. Universidad Nacional de Cuyo.

https://bdigital.uncu.edu.ar/objetos_digitales/11708/zubiria-cartasesteticasrevision2019.pdf

Sedlmayr, H. (1959). El arte descentrado: las artes plásticas de los siglos XIX y XX como síntoma y símbolos de la época, Labor.

Soloviev, V. (1983). Il significato universale dell'arte. En V. Soloviev. Il significato dell'amore e altri scritti. La Casa di Matriona.

Stein, E. (1968, 2012 $\left.{ }^{6}\right)$. La donna. Città Nuova.

Tanzella-Niti, G. y Strumia, A. (edd.) (2002). Bellezza. En Dizionario Interdisciplinare di Scienza e Fede, vol. I, Urbaniana University Press-Città Nuova (1ºd., pp. 167-181).

Tomás de Aquino (s.f.), Summa Theologiae, I, q.5, a.4. 